\title{
The investigation of malabsorption
}

\author{
CLIFFORD F. HAWKINS \\ From the Queen Elizabeth Hospital, Birmingham
}

Malabsorption can seldom be investigated by one test alone, for the small intestine has a myriad of functions: digestive, absorptive, synthetic, and excretory. Multiple tests-small-intestinal function testsare needed like liver function tests.

Each new diagnostic test has a similar career. Hailed as the answer to the physician's prayer, the first report shows distinct separation between normal and abnormal (Fig. 1a). As later papers appear, the two groups merge and records appear of similar findings in other conditions (Fig. 1b); then occurs a disappointing overlap between abnormals and normals (Fig. 1c). This is the story of jejunal biopsy and also of various tests of absorption where numerous substances have been tried but abandoned because of lack of specificity. The discriminant index of a single test may not be great, but when two or more tests are combined a higher statistical significance is more likely. Sometimes a normal result may provide stronger evidence in excluding a disorder than an abnormal one which is common to other conditions.

No test for malabsorption carries the stamp of certainty. Steatorrhoea itself may be absent not only

a

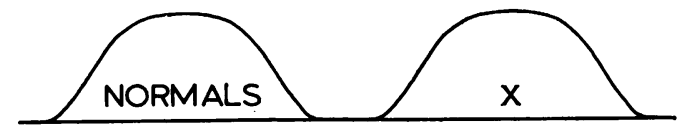

b
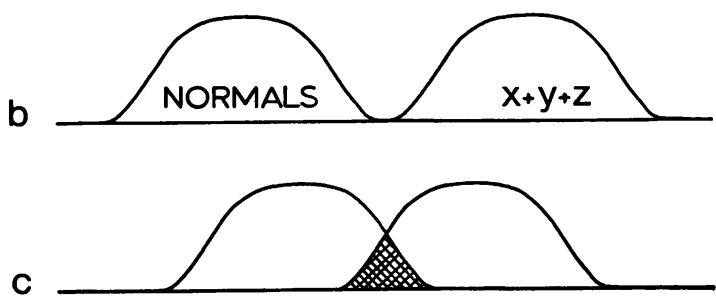

Fig. 1 Problems arising in the discriminating value of tests; $x, y$, and $z$ represent disorders where the test is abnormal. in the stagnant bowel syndrome but in coeliac disease whether childhood (Cameron, Astley, Hallowell, Rawson, Miller, French, and Hubble, 1962) or adult (Samloff, Kelley, Logan, and Terry, 1964; Pink and Creamer, 1967). Hubble (1963) stated that each of the screening tests-faecal fat, xylose excretion, and small-intestinal radiographs-might fail to identify from 10 to $30 \%$ children with coeliac disease, and McNeish (1969) found that $15 \%$ of 200 coeliacs had one or more negative tests. The ideal test should be simple, repeatable, and discriminating.

\section{Examination of Structure}

\section{RADIOGRAPHIC METHODS}

A faulty barium progress meal is a common cause for missed diagnosis in patients with malabsorption. Indeed, some radiographs are a mere travesty of the proper progress meal. Performed by an uninterested radiologist, pools of barium flood the abdomen with hardly any coils of bowel visible.

The small gut is, of course, the most difficult and laborious part of the alimentary tract to $x$-ray. Its length, the series of superimposed loops, and lack of landmarks to guide the radiologist as to whether barium has passed any particular segment, are obvious problems. Metoclopramide is a useful 'accelerator' which speeds the passage of barium and saves the radiologist's time (Howarth, Cockel, Roper, and Hawkins, 1969). For once the obese patient is easier to $x$-ray, as mesenteric fat helps to separate loops of bowel (F. H. Howarth, personal communication). Diagnosis of coeliac disease is supported when the mean diameter of the three widest loops of jejunum is $\mathbf{3 0} \mathrm{mm}$ or more (Laws, Booth, Shawdon, and Stewart, 1963). However, a normal barium meal may occur in a few patients. Flocculation of barium, especially early in the meal, before two hours, is a strong pointer to coeliac disease. The degree of flocculation depends partly upon the stability of the contrast medium and micropulverization of barium sulphate has much improved this. Flocculation may also vary from film to film in the same series so that judgement should rarely be 
derived from a single radiograph. Two contrast media are widely used in the UK and elsewhere, Micropaque and Raybar-the latter being the more resistant to flocculation. Micropaque is usually employed for a barium progress meal and this reveals flocculation more readily than will Raybar. If so much flocculation occurs that it interferes with anatomical definition, then the meal may be profitably repeated with Raybar when the other signs of coeliac disease-jejunal dilatation and thickening of the primary mucosal folds-may be defined. Pictures are usually taken every $\mathbf{1 5}$ minutes for one hour, and then each half-hour, or as indicated by screening. A close liaison between clinician and radiologist pays dividends.

Localized lesions may need closer examination by a small bowel 'enema'; a misnomer for an enema is defined as 'a liquid injected into the rectum' (Dorland, 1965). After intubation, $100 \mathrm{ml}$ Micropaque followed by a cellulose colloid solution such as one-half per cent Prepacol (water alone is absorbed too quickly) are injected. A barium enema is sometimes needed to outline the terminal ileum and is usually the only way of detecting a gastrocolic or other fistula, for barium passes through the small intestine normally during a meal either because a plug of mucosa forms a valve or due to pressure gradients across the fistula. Selective angiography may define the extent of Crohn's disease or the nature of a tumour but is otherwise of little use. Lymphangiography may reveal retroperitoneal lesions or enlarged paraaortic lymph nodes as in reticulosis or Whipple's disease.

\section{JEJUNAL BIOPSY}

Jejunal biopsy is the final arbiter in most patients suspected of malabsorption, whether children or adults. Indeed, no one should be prescribed a glutenfree diet unless this is suggested by biopsy findings. The specimen should be examined macroscopically within two hours in formol-saline either by a dissecting microscope, a low-power lens, or a hand lens. If the mucosa is flat, a gluten-free diet can be started at once before waiting from the histological report. Also this inspection, best carried out by pathologist as well as clinician, is a useful check in case sections are cut obliquely, when a normal can be converted to a flat biopsy.

Observer's error in interpreting biopsies has not been given much attention but it is probably least with the flat mucosa and reduced by the experience and interest of the pathologist. The advantage of the pathologist working closely with the clinician is immense, as shown by the numerous joint publications in this field. A jejunal biopsy carried out casually by the inexperienced is usually a waste of the operator's and patient's time. Absolute measurements, such as villous height and width, height of epithelial cells, total mucosal thickness, and mitotic index of the crypt cell population, may increase accuracy of interpretation but are beyond the capacity of most pathological laboratories. Electron microscopy, except for monitoring the success of therapy in Whipple's disease, is a research tool and scanning electron microscopy only provides a highly magnified dissecting microscopic appearance.

When jejunal biopsy was started, its specificity was not doubted. Thus, the title of an early article by Rubin and his group (Rubin, Brandborg, Phelps, and Taylor, 1960) was 'The apparent identical and specific nature of the duodenal and proximal jejunal lesion in coeliac disease and idiopathic sprue'. Ten years later, another paper from the same centre (Rubin, Eidelman, and Weinstein, 1970) described its nonspecific nature and how 'the bounds of normality overlap those of disease .... The normal range itself is wide. So the villi of healthy natives of Birmingham are more likely to resemble fingers or leaves than those of the population of Pakistan where damage, perhaps by parasites, irritant foods, or malnutrition may convert villi to ridges or convolutions. Jejunal mucosal lesions have been reported in many conditions: ulcerative colitis, Crohn's disease, small-intestinal diverticulosis, hepatitis, pernicious anaemia, after gastrectomy, kwashiorker, chronice renal failure, skin disease, and from drugs. However, the significance in some of these may be doubtful especially when changes are slight. For the reports sometimes occurred before the full range of normality was known, and to what extent systemic illness itself can affect the intestinal mucosa is still unclear. Jejunal biopsy is usually diagnostic in coeliac disease (childhood or adult), Whipple's disease, lymphangiectasia, a- $\beta$-lipoproteinaemia, hypogammaglobulinaemia, and when parasites such as giardia are present.

The characteristic lesion in coeliac disease is the flat biopsy, but less severe changes of mucosal transformation are present in many patients, described as partial villous atrophy (p. 108). One wonders how close to normality the mucosa in untreated coeliacs can approach if small amounts of gluten are ingested as by those eating little bread or in immigrants taking mainly rice. Another cause for a normal or near normal biopsy might be a patchy lesion in the duodenum or jejunum, as every form of biopsy is liable to variation from sampling. Whatever appearance is seen, exact diagnosis depends on demonstrating sensitivity to gluten, for the primary disturbance is biochemical; then the mucosa is normal-other signs depend upon secondary morphological changes. Unfortunately no simple test has yet been found to 
detect gluten sensitivity, and gliadin curves in the blood are of no help. Therefore a trial of the glutenfree diet is necessary and may have to be given for six months before being abandoned as unsuccessful. Success is shown by weight gain, loss of diarrhoea, and the return to normal of haematological and biochemical abnormalities. Improvement on any diet may be fortuitous or due to a placebo effect. So a provocative or challenge test is employed by reintroducing gluten, either as a normal diet or by powdered gluten. Gluten sensitivity is proved by clinical relapse or changes in parameters such as the jejunal biopsy (Pollock, Nagle, Jeejeebhoy, and Coghill, 1970), xylose test, or faecal fat excretion. Many people are probably being treated unnecessarily with gluten-free diets and so deprived needlessly of the pleasures of the table (Hawkins, 1970).

Failure to respond to the gluten-free diet, which may occur in $30 \%$ of patients, does not exclude adult coeliac disease. For example, a man aged 50 died under my care and the diagnosis was confirmed at necropsy; he had been treated in hospital continuously with a gluten-free diet supervised by a dietician for four months and had received a course of antibiotics. Yet his son who presented later with the same condition responded immediately to the withdrawal of gluten. Lack of response to the withdrawal of gluten may be due to a faulty diet, to extensive involvement of the intestinal mucosa or secondary pancreatic deficiency (Pink and Creamer, 1967), to malignant change, because of a wrong diagnosis, and for unknown reasons.

\section{Small-intestinal Function Tests}

A simple test of intestinal function would enable patients to be screened before undertaking elaborate and time-consuming investigations. Many test substances such as butter, fat, olive oil, glycerine, vitamins, and sugars have been tried but found wanting. Tolerance tests, where a rise in concentration of the substance in the blood is plotted, are often erroneous because other factors, such as rapid deposition in tissues, cause the flat curves expected with faulty absorption. Hence the vitamin A tolerance test has been abandoned and the glucose tolerance test is only used for diagnosing pancreatic steatorrhoea, when a high curve is common.

\section{JEJUNUM}

\section{$D$-xylose excretion test}

The only substance that has stood the test of time is d-xylose. Absorbed only in the jejunum and relatively inactive metabolically, it can be used to screen patients for coeliac disease (childhood and adult) and tropical sprue. Early reports of its value (Benson, Culver, Ragland, Jones, Drummey, and Bougas, 1957; Fowler and Cooke, 1960) have been supported by later workers. For example, Mann, Brown, and Kern (1970) found that excretion of xylose was abnormally low in 20 of their 21 patients and pointed out that this was so in all 46 patients in four series reported in the literature (Bayles, Yardley, and Hendrix, 1963; Benson, Kowlessar, and Sleisenger, 1964; Brooks, Powell, and Cerda, 1966; Finkel, Gelb, Cohen, and Janowitz, 1967).

Xylose excretion is normal in pancreatic steator rhoea. It may be diminished in the stagnant bowel syndrome. Goldstein and his colleagues (Goldstein, Karacadag, Wirts, and Kowlessar, 1970) believed that this was due to consumption of xylose in the bowel by bacteria. If so, xylose breakdown must be surprisingly quick to affect the five-hour test. The rate of disappearance of xylose from cultures of Gram-negative organisms in our laboratory was too slow to alter results significantly over five hours but conditions may be different in the bowel itself; we thought that minor mucosal damage was the more likely explanation. Xylose excretion is also reduced by solution in fluid compartments as occur in effusions, ascites and pregnancy.

Five grams of xylose is now given instead of $25 \mathrm{~g}$ for this is as accurate and is less likely to cause osmotic diarrhoea from surplus xylose in the gut (Sammons, Morgan, Frazer, Montgomery, Philip, and Phillips, 1967). Estimation of xylose in urine collected at two hours is more discriminating than with a five-hour specimen (Sammons et al, 1967; Kendall, 1970), probably because the earlier specimen tests the speed of absorption rather than the quantity absorbed. Every result must be corrected for age, as diminished excretion in later life is expected. By using intravenous $(50 \mathrm{ml} 10 \%$ solution) as well as oral xylose, Kendall (1970) showed that this was due to reduced renal capacity, since xylose excretion correlates with glomerular filtration rate as well as with jejunal absorption.

The commonest error in performing the xylose test lies in the method of collecting the urine. Patients wander absentmindedly to the WC and lose a specimen; to avoid this men should be told to put their pants on back to front as a reminder, and women should fasten their garments with a safety pin. The doctor, rather than a busy junior nurse, should tell the patient what is involved in collecting a timed specimen at 2 and 5 hours. If xylose is not estimated at once, the urine should be kept in a refrigerator or a preservative $(20 \mathrm{ml}$ of $2.5 \%$ formaldehyde in isopropyl alcohol) added, as bacterial action overnight may account for false low readings. The normal excretion of xylose two hours 


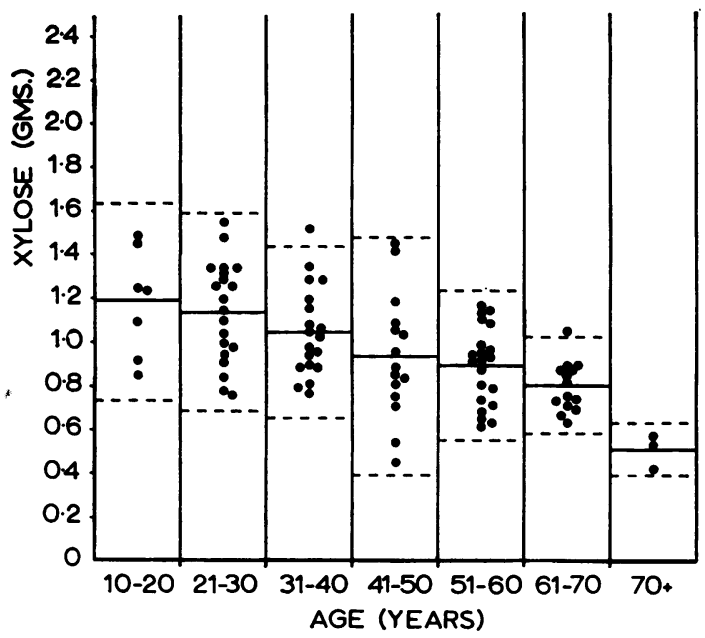

Fig. 2 Excretion of xylose two hours after giving $5 \mathrm{~g}$ orally (after Kendall, 1970).

after $5 \mathrm{~g}$ given orally in each decade is shown in Figure 2.

Folic acid deficiency (p.66)

A low serum folate (below $3 \mathrm{ng} / \mathrm{ml}$ ) is the most useful single screening test for coeliac disease (childhood or adult) and tropical sprue. It is simple for the clinician though difficult for the laboratory and is virtually always low in these conditions (Dormandy, Waters, and Mallin, 1963; Magnus, 1966). There are two disadvantages. First, a low folate may be due to other causes: dietetic, drugs (Waxman, Corcino, and Herbert, 1970) such as anticonvulsants, antibiotics, barbiturates, oral contraceptives, immunosuppressives, folic acid antagonists, ethanol, or systemic disease like rheumatoid arthritis and malignancy, and pregnancy. Secondly, assay of serum folate in the laboratory can be unreliable. If results of estimating serum vitamin $\mathbf{B}_{12}$ at different centres are compared, readings correlate well. This may not be so with folate, for unexpectedly low readings may be obtained at one hospital using the identical method; this may remain unexplained and need correction as levels otherwise are similar. The lower level for normals expected in any individual laboratory should therefore be obtained, and this is sometimes 2.5 instead of $3.0 \mathrm{ng} / \mathrm{ml}$ (Lactobacillus case $i$ assay). Raised folic acid levels have been reported in the blind loop syndrome (Hoffbrand, Tabaqchali, and Mollin, 1966) presumably due to synthesis of $L$. case $i$ active material by the bacteria and its subsequent absorption.

Whole blood folate was regarded by McNeish and
Willoughby (1969) as more discriminating for coeliac disease in children. This measures the state of folate nutrition over the previous 120 days, for folate is incorporated into red blood cells as they form in the marrow, rather than varying according to dietetic or other factors as with serum folate-so it is less labile. Ninety per cent of whole blood folate is contained in red cells and this is a more stable form which, in contrast to serum folate, is not denatured by air, light, and heat. In estimating whole blood folate the active form has to be released by exposing the blood to plasma conjugase (Toennies, Usdin, and Phillips, 1956). If anaemia is present, results have to be corrected according to the haematocrit. Folate deficiency is diagnosed if the red cell folate is less than $100 \mathrm{ng} / \mathrm{ml}$ packed red blood cells (Mollin and Hoffbrand, 1965) - and it is less than $50 \mathrm{ng} / \mathrm{ml}$ in coeliac disease (McNeish and Willoughby, 1969). Forty medical students were studied by Chanarin (1970) and levels found between 116 and $410 \mathrm{ng} / \mathrm{ml}$.

Methods to assess absorption of folic acid are less satisfactory. A criticism of the Girdwood method (Girdwood and Delamore, 1961) is the large test dose of $5 \mathrm{mg}$, which is too insensitive to detect small differences in absorption (Luhby and Cooperman, 1964). Also, Chanarin's method (Chanarin, MacGibbon, O'Sullivan, and Mollin, 1959) is a tolerance test measuring blood levels, so rapid plasma clearance may cause a flat curve like malabsorption. Testsô using pterylpolyglutamites-food folates that are? deconjugated by the enzyme folate conjugase contained in the jejunal mucosa-are being developed and may prove more specific.

\section{ILEUM}

Malabsorption of vitamin $B_{12}(p .60)$

A low serum vitamin $B_{12}$ (below $150 \mathrm{pg} / \mathrm{ml}$ ) is expected in certain forms of malabsorption. However, this change may be late because body stores last four years in contrast to folate which may be depleted after three or four weeks; so malabsorption of $\mathrm{B}_{12}$ is best detected by absorption studies using the cobalt-labelled vitamin. A low level of vitamin $B_{12}$ is reported in up to $50 \%$ of patients with adult coeliac disease probably because of extension of mucosal damage to the ileum where $B_{12}$ is absorbed (Booth and Mollin, 1959).

Other causes of low serum vitamin $\mathbf{B}_{12}$ are as follows: (1) lack of intrinsic factor: pernicious anaemia and partial and total gastrectomy; (2) bacterial contamination of small intestine: stricture, blind loop syndrome as in stagnant afferent loop after partial gastrectomy, diverticulosis of small intestine, and fistulae; (3) damage to ileum: Crohn's disease and resection; (4) congenital: rare syndrome 
of vitamin $\mathbf{B}_{12}$ malabsorption associated with proteinuria in children, juvenile pernicious anaemia where intrinsic factor is absent though $\mathrm{HCl}$ is normal; (5) other causes: nutritional as in tropical megaloblastic anaemia from lack of animal protein, fish tapeworm (Diphyllobothrium latum), pancreatitis (rare) perhaps due to acid $p \mathrm{H}$ in intestine from lack of bicarbonate.

Raised levels of vitamin $B_{12}$, providing the patient is not receiving the vitamin in some form, point to hepatic disease; storage of $\mathrm{B}_{12}$ may be affected by the damaged liver.

Measurement of the absorption of $B_{12}$ (assuming that intrinsic factor production is normal) is a useful test of ileal function. The test dose of vitamin $B_{12}$ must not be more than $2 \mu \mathrm{g}$ if intrinsic factor dependent absorption is measured, for with larger doses diffusion may occur. For doses up to $2 \mu \mathrm{g}$, the percentage absorbed is inversely proportional to dose, so that a higher percentage of $0.5 \mu \mathrm{g}$ will be absorbed than of $2 \mu \mathrm{g}$. Tests are carried out fasting. Suitable methods in current use are as follows:

(1) The Schilling test where urinary excretion is measured. A disadvantage is giving $1,000 \mu \mathrm{g} B_{12}$ as a 'flushing dose'. This treats the patient and prevents the use of physiological doses of the vitamin in further studies.

(2) The hepatic uptake test described by Glass in which radioactivity over the liver is measured five to seven days after giving labelled vitamin $\mathbf{B}_{\mathbf{1 2}}$ orally. This avoids the need to collect urine and does not require a therapeutic dose of vitamin $B_{12}$. Liver disease may affect hepatic uptake.

(3) Whole body counting using a scintillation counter is now regarded by many as the most sensitive and reliable method. No collection of urine or blood is required and smaller amounts of labelled vitamin $B_{12}$ are used because most external radiation from natural sources is excluded.

CHEMICAL ESTIMATION OF FAECAL FAT Chemical estimation of faecal fat is a useful guide to small-intestinal function. The amount of faecal fat is more likely to reflect the extent of damage to the bowel than to correlate with the appearance of a random jejunal biopsy. Faecal fat is also a useful yardstick for measuring the effect of therapy. Steatorrhoea and malabsorption are not synonymous. For example, in pancreatic steatorrhoea absorption is normal. Nor does the absence of steatorrhoea in adult coeliac disease indicate that other substances are being absorbed normally. Malabsorption of iron (McGuigan and Volwiler, 1964) and osteomalacia without steatorrhoea (Moss, Waterhouse, and Terry, 1965) have been recorded and this probably applies to most other substances commonly affected in adult coeliac disease.

Rest in bed often induces constipation even in the most diarrhoeic subject, so stool collection should begin immediately after admission to hospital and before other investigations. Stools are collected continuously for three or four days. A ward diet, which contains about $70 \mathrm{~g}$ fat daily, is satisfactory, but for special studies, when 50 or $100 \mathrm{~g}$ fat daily is given, a dietician should be consulted. A diet containing $100 \mathrm{~g}$ fat daily will also allow borderline cases to be detected more easily. The upper limit of faecal fat excretion is $7 \mathrm{~g} / 24$ hours. When long-term studies are undertaken, a three-day mean is run continuously to avoid errors from irregular evacuation of the colon.

Two errors commonly cause false normal figures for faecal fat. First, an ill patient may not eat enough. Secondly, collection of stools may not be complete: nurses are conditioned to disposal as rapidly as possible and the ambulant patient may escape to the WC. We have carried out many studies where the patient collects stools at home. Special cans, ${ }^{1}$ one for every 24 hours, are given to the patient; each fits exactly within the lavatory seat and is sealed after use by cellotape. The cans are delivered to the biochemical laboratory and accuracy of collection is often as good as in a metabolic ward. These cans are also useful to have on the ward for they fit into a commode.

Modern rapid methods for estimating faecal fat as fatty acids have lightened the burden of the biochemical laboratory and a technician with anosmia is not essential. The van de Kamer method (van de Kamer, ten Huinink, and Weyers, 1949) reports results mainly as long-chain triglycerides with 10 or more carbon atoms. Results are calculated as $\mathrm{C}_{18}$, which is stearic acid with a molecular weight of 284 instead of actual molecular weights according to chain lengths of individual fatty acids. Hence, when medium-chain triglycerides are substituted for other fat in the diet, the faecal fat will fall dramaticallynot necessarily because of improved absorption but because medium-chain triglycerides are underestimated by the van de Kamer method (J. M. French, personal communication).

Techniques using fats labelled with radioactive isotopes are too inaccurate to replace the chemical method. Measurement of ${ }^{131}$ iodine in blood or urine does not necessarily reflect the amount of fat absorbed, for the label may become separated and false normal results follow. Faecal radioactivity is more reliable than radioactivity in blood or urine but the need for collecting stools does not endear it as a

${ }^{1}$ Obtainable from Wilson Products and Spinning Co Ltd, 188 Edward Road, Birmingham 12. 
simple screening test. Nor are radioactive labelled fats of any value in distinguishing pancreatic and small bowel disease.

\section{BLOOD TESTS}

Anaemia is a common symptom of malabsorption though changes in the blood may be slight. Macrocytosis in the films, and indicated by a mean cell volume above $96 \mathrm{c} \mu$, is the commonest anomaly (Cooke, Peeney, and Hawkins, 1953). This macrocytosis may be masked by iron deficiency so that a normocytic and hypochromic anaemia alone is seen, or red cells showing either macrocytosis or iron deficiency may coexist; this dimorphic appearance prompts the experienced haematologist to diagnose adult coeliac disease.

A raised ESR (Westergren) may point to granulomatous or other bowel disease but occurs in occasional patients with adult coeliac disease for unknown reasons. Haemorrhage, even profuse from the gastrointestinal tract, may complicate malabsorption and is not due to scurvy but to vitamin $\mathrm{K}$ deficiency. The prothrombin time may therefore help and is always indicated before undertaking jejunal biopsy.

Biochemical tests-serum sodium, chloride, potassium, magnesium, and urea-should be performed as for chronic diarrhoea. Hypoproteinaemia, detected by the serum albumin, is likely to be due to protein-losing enteropathy rather than to defective synthesis and can be investigated by labelling the patient's own albumin with radioactive chromium (p. 45). The serum calcium, alkaline phosphatase, and phosphate are essential for diagnosing osteomalacia or latent tetany. Estimation of immunoglobulins, when immunodiffusion techniques are available, may help. A significant increase in $\operatorname{IgA}$ is common in untreated adult coeliac disease and higher levels may occur if malignant change develops (Asquith, Thompson, and Cooke, 1969). IgM levels are depressed, perhaps because gluten or other antigenic dietary components exert a suppressive effect on IgM production (Kenrick and Walker-Smith, 1970).

Other special tests that may be required are discussed elsewhere. An indirect pointer to excess bacteria in the small intestine can be given by urinary indican, though this test is fickle and depends upon the patient eating enough tryptophane. Bacterial counts in samples of jejunal fluid provide a direct approach (p. 130) but culturing anaerobic organisms, which is needed for defining the organisms, is beyond the scope of a routine bacteriological laboratory. Disaccharidase deficiency should always be considered (p. 22.) A simple screening test for lactase deficiency is to give every patient with diarrhoea a drink containing $50 \mathrm{~g}$ lactose on admission to hospital: borborygmi or worsening of diarrhoea will suggest it and their absence exclude it. Deconjugation of bile salts in intestinal fluid can be tested by thin layer chromatography or by more precise methods (p. 77). Laparotomy may be the final court of appeal in some patients, being the only way of detecting occult fistulae or malignant disease.

Known causes of malabsorption continue to multiply and knowledge of the physiology of the small bowel increases. The most challenging case is the one that fits into no known category, for new conditions must be awaiting discovery.

I would like to thank my colleagues Drs F. H. Howarth and M. J. Meynell for their help.

\section{References}

Asquith, P., Thompson, R. A., and Cooke, W. T. (1969). Serumimmunoglobulins in adult coeliac disease. Lancet, 2, 129-131.

Bayless, T. M., Yardley, J. H., and Hendrix, T. R. (1963). Adult coeliac disease: treatment with a gluten-free diet. Arch. Intern. Med., 111, 83-92.

Benson, G. D., Kowlessar, O. D., and Sleisenger, M. H. (1964). Adult celiac disease with emphasis upon response to the gluten-free diet. Medicine (Baltimore), 43, 1-40.

Benson, J. A., Jr., Culver, P. J., Ragland, S., Jones, C. M., Drummey, G. D., and Bougas, E. (1957). The d-xylose absorption test in malabsorption syndromes. New Engl. J. Med., 256, 335-339.

Booth, C. C., and Mollin, D. L. (1959). The site of absorption of vitamin $B_{12}$ in man. Lancet, $1,18-21$

Brooks, F. P., Powell, K. C., and Cerda, J. J. (1966). Variable clinical course of adult coeliac disease. Arch. intern. Med., 117, 789794.

Cameron, A. H., Astley, A. S., Hallowell, M., Rawson, A. B., Miller, C. G., French, J. M., and Hubble, D. V. (1962). Duodenojejunal biopsy in the investigation of children with coeliac disease. Quart. J. Med., 31, 125-140.

Chanarin, J., MacGibbon, B. M., O'Sullivan, W. J., and Mollin, D. L. (1959). Folic-acid deficiency in pregnancy. The pathogenesis of megaloblastic anaemia of pregnancy. Lancet, 2, 634-639.

Cooke, W. T., Peeney, A. L. P., and Hawkins, C. F. (1953). Symptoms. signs and diagnostic features of idiopathic steatorrhoea. Quart. J. Med., 22, 59-77.

Dorland, W. A. N. (1965). The American Illustrated Medical Dictionary, 24th ed. Saunders, Philadelphia and London.

Dormandy, K. M., Waters, A. H., and Mollin, D. L. (1963). Folic acid deficiency in coeliac disease. Lancet, 1, 632-635.

Finkel, M., Gelb, A. M., Cohen, N. M. O., and Janowitz, H. D. (1967). Long-term follow-up study in idiopathic steatorrhoea. Amer. J. Gastroent., 47, 35-40.

Fowler, D., and Cooke, W. T. (1960). Diagnostic significance of d-xylose excretion test. Gut, 1, 67-70.

Girdwood, R. H., and Delamore, I. W. (1961). Observations on tests of folic acid absorption and clearance. Scot. med. J., 6, 44-59.

Goldstein, F., Karacadag, S., Wirts, C. W., and Kowlessar, O. D. (1970). Intraluminol small-intestinal utilization of d-xylose by bacteria. Gastroenterology, 59, 380-386.

Hawkins, C. F. (1970). Personal view. Brit. med. J., 4, 362.

Hoff brand, A. V., Tabaqchali, S., and Mollin, D. L. (1966). High serum-folate levels in intestinal blind loop syndrome. Lancet, 1, 1339-1342.

Howarth, F. H., Cockel, R., Roper, B. W., and Hawkins, C. F. (1969) The effect of metoclopramide upon gastric motility and its value in barium progress meals. Clin. Radiol., 20, 294-300.

Hubble, D. V. (1963). Diagnosis and management of coeliac disease in childhood. Brit. med. J., 2, 701-706.

Kamer, J. H. van de, Huinink, H. ten B., and Weyers, H. A. (1949). Rapid method for the determination of fat in faeces. J. biol. Chem., 177, 347-355. 
Kendall, M. J. (1970). The influence of age on the xylose absorption test. Gut, 11, 498-501.

Kenrick, K. G., and Walker-Smith, J. A. (1970). Immunoglobulins and dietary protein antibodies in childhood coeliac disease. Gut, 11, 635-640.

Laws, J. W., Booth, C. C., and Shawdon Stewart, J. S. (1963). Correlation of radiological and histological findings in idiopathic steatorrhoea. Brit. med. J., 1, 1311-1314.

Luhby, A. L., and Cooperman, J. M. (1964). Folic acid deficiency in man and its inter-relationship with vitamin $B_{12}$ metabolism. In Advances in Metabolic Disorders, edited by $\mathbf{R}$. Levine and $\mathbf{R}$. Luft, Vol. 1, pp. 263-334. Academic Press, New York and London.

Magnus, E. N. (1966). Low serum and red cell folate activity in adult celiac disease. Amer. J. dig. Dis., 11, 314-319.

Mann, J. G., Brown, W. R., and Kern, F. (1970). The subtle and variable clinical expressions of gluten-induced enteropathy (adult coeliac disease, non-tropical sprue). An analysis of twenty-one consecutive cases. Amer. J. Med., 48, 357-366.

McGuigan, J. E., and Volwiler, W. (1964). Celiac-sprue: malabsorption of iron in the absence of steatorrhoea. Gastroenterology, 47, 636-641.

McNeish, A.S. (1969). Quoted in McNeish and Willoughby (1969).

McNeish, A. S., and Willoughby, M. L. M. (1969). Whole-blood folate as a screening test for coeliac disease in childhood. Lancet, 1, 442-443.

Mollin, D. L., and Hoffbrand, A. V. (1965). The diagnosis of folate deficiency. Ser. Haematol., 3, 1-18.

Moss, A. J., Waterhouse, C., and Terry, R. (1965). Gluten-sensitive enteropathy with osteomalacia but without steatorrhoea. New Engl. J. Med., 272, 825-830.

Pink, I. J., and Creamer, B. (1967). Response to a gluten-free diet of patients with coeliac syndrome. Lancet, 1, 300-304.

Pollock, D. J., Nagle, R. E., Jeejeebhoy, K. N., and Coghill, N. F. (1970). The effect on jejunal mucosa of withdrawing and adding dietary gluten in cases of idiopathic steatorrhoea. Gut, 11, 567-575.

Rubin, C. E., Brandborg, L. L., Phelps, P. C., and Taylor, H. C. (1960). Studies of coeliac disease. 1. The apparent identical and specific nature of the duodenal and proximal jejunal lesion in coeliac disease and idiopathic sprue. Gastroenterology, 38, 28-49.

Rubin, C. E., Eidelman, S., and Weinstein, W. M. (1970). Sprue by any other name. Gastroenterology, 58, 409-413.

Samloff, I. M., Kelley, M. L., Logan, V. W., and Terry, R. (1964). Severe histopathological lesion of sprue in patients with minimal evidence of malabsorption. Ann. intern. Med., 60, 673-679.

Sammons, H. G., Morgan, D. B., Frazer, A. C., Montgomery, R. D., Philip, W. M., and Phillips, M. J. (1967). Modification in the xylose absorption test as an index of intestinal function. Gut, 8, 348-353.

Toennies, G., Usdin, E., and Phillips, P. M. (1956). Precursors of the folic acid-active factors of blood. J. biol. Chem., 221, 855-863.

Waxman, S., Corcino, J. J., and Herbert, V. (1970). Drugs, toxins and dietary amino acids affecting vitamin $\mathrm{B}_{12}$ or folic acid absorption or utilisation. Amer. J. Med., 48, 599-608. 